\title{
Influence of Capacitances on the Impedance-Based Methods for SLG Fault Location in Distribution Networks
}

\author{
S. Herraiz ${ }^{1}$, J. Meléndez ${ }^{1}$ and J. Sánchez ${ }^{2}$ \\ ${ }^{1}$ Institute of Computer Science and Applications, University of Girona, Spain \\ Phone:+0034 972 418884, e-mail: sherraiz@eia.udg.edu, quimmel@eia.udg.edu \\ 2 ENDESA DISTRIBUCION, Spain, e-mail: jslosada@fecsa.es
}

\begin{abstract}
Fault location has been studied deeply for transmission lines due to its importance in power systems. Nowadays the problem of fault location on distribution systems is receiving special attention mainly because of the power quality regulations. In this context, this paper analyses the influence of the capacitance of cables and compensation capacitor banks when impedance-based algorithms are used to calculate the location of single-line-to-ground (SLG) faults,
\end{abstract}

\section{Key words}

Fault location, voltage sags, power quality monitoring.

\section{Introduction}

Traditionally, fault location techniques have been developed for transmission electric lines due to the importance they have in the electric system and the impact that faults would have on these kinds of lines. More recently, distribution lines have been taken more into account due to the improvement in the quality of power supply, derived from operating in a deregulated environment and the high competition between companies. Due to the growing interest in power quality, digital recorders that capture power quality phenomena have become an important tool, so measurements of voltages and currents before and during the fault are easily available and suitable to be used to estimate where the origin of the fault is located.

Among the different power quality phenomena, disturbances known as voltage sags are the most common. Voltage sag is a temporary decrease in the RMS voltage magnitude between $10 \%$ and $90 \%$ of the declared voltage for durations of one-half cycle to 1 minute [1]. Its frequency of occurrence is between a few tens and several hundreds times per year, its duration of mostly less than $1 \mathrm{~s}$ and voltage drops rarely below $40 \%$ [2]. They can be of diverse origin (network operation, faults and short circuits, weather, etc.), and located in the entire power system (transmission, distribution or consumers). In this work we focused on those sags originated by faults in the distribution system and registered by power quality monitors installed in substations, at medium voltage (MV) level.

Most of the current interest in voltage sags is directed to which are due to short-circuit faults, so it is interesting to find where the origin of disturbance sources is located. In literature, different methods for estimating the location of distribution line faults are described. One of these methods uses the fundamental frequency voltages and currents measured at the origin terminal of the line. It is known as impedance-based method, since it consists of calculating line impedances as seen from the line origin terminal and estimating distances of the faults [1]. Algorithm proposed by R. Das uses voltages and currents measured at a line terminal before and during the fault [3].

Since these methods are based in the knowledge of the network model, the present paper proposes the consideration of the capacitance due to the cables and the compensation capacitor banks in the modelling of the network and its influence on fault location algorithms based on impedance calculation, such as the proposed by [3], when single-line-to-ground faults are studied.

The paper has been organized as follows. First, a brief description of the problem is presented. Next, the influence of capacitances is analyzed starting from two fault registers. Finally, conclusions of the work are summarized.

\section{Capacitances and single-line-to-ground fault location}

The power distribution system has a radial topology and it has a high degree of heterogeneity as a result of the existence of different kind of conductors with different impedance, both overhead and cable lines and lines with different length. There is also heterogeneity in the loads. As an example, Figure 1 shows a typical power distribution system starting from the substation power, which feeds four different lines, with a power quality monitor installed in MV level. 


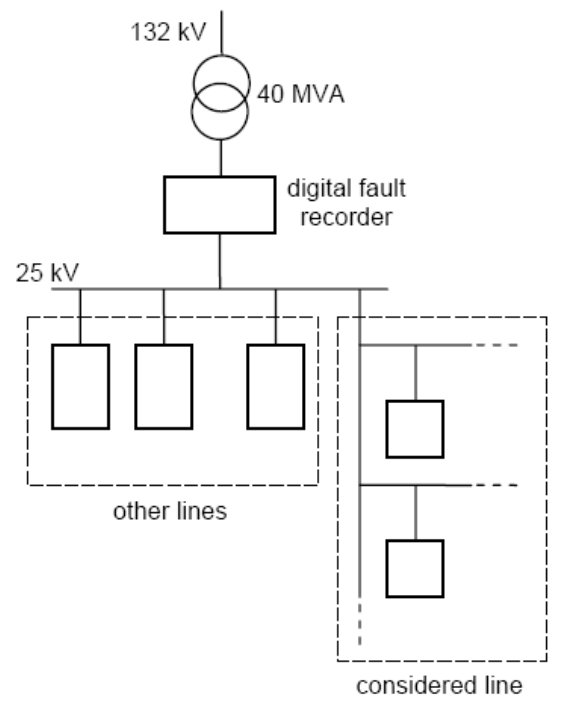

Fig. 1. Scheme of the power distribution system.

In fault location algorithms that are impedance-based methods, the root mean square values (RMS) of the fundamental current and voltage measured at the substation during the fault are used to estimate the impedance seen from the measuring point [2][3]. Then, the faulty section is estimated following an iterative procedure: the impedance obtained from the line model considering a possible fault in each node of the network is compared with the equivalent impedance calculated from measurements. A consistency test allows isolating the possible affected sections. The exact point in the section line could be estimated according to the reactance analysis as it is described in [3].

Majority of those methods have been designed to operate with three-phase faults and consequently assumes some simplifications when the line is modelled. Based on these methods some authors have extended the fault location methods to unbalanced faults. Considering a single-phase voltage sag, the location of the fault by applying R. Das algorithm [3] can be estimated by comparing the apparent reactance computed by using the faulted phase voltage and current, and the modified reactance of the line between the substation and the location of the fault, with:

$X_{m r}^{m}=X_{1 m r}+\frac{X_{0 m r}-X_{1 m r}}{3}$

where, $X_{0 \mathrm{mr}}$ and $X_{1 \mathrm{mr}}$ are the zero and positive sequence reactance of the section.

By using this method as in [3], several factors may been not considered and differences between the real fault location and the result obtained by the algorithm can appeared due to the model considered in the analysis.

In case of a single-line-to-ground fault, the capacitance due to the cables that are present in the power distribution system takes part in its behaviour during the fault. This capacitance corresponds to the faulted line but also to the non-faulted lines that are connecting to the same busbar. During the fault this capacitances gives a path for the circulation of fault current, so under such a situation

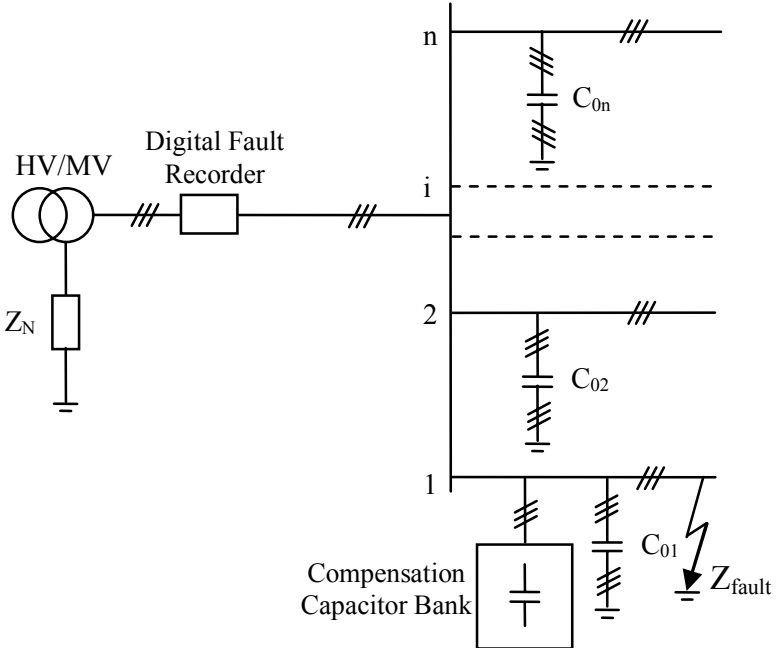

Fig. 2. SLG fault in a power distribution system.

capacitance of those cables can get to be important depending on the kilometres of cable installed in the system.

Another consideration that can be made is related to the possible compensation capacitor bank at the beginning of the line, that drives to a difference between the current measured at the substation and the current in the faulted line. Since the latter current is that would be considered when the fault location algorithm is used, differences between real and estimated fault location can appear.

Figure 2 shows the configuration of a power distribution system with a single-line-to-ground fault in one of the feeders, the capacitances due to cables $\left(C_{01}, C_{02} \ldots C_{0 \mathrm{n}}\right)$ and a compensation capacitor bank in the faulted feeder.

\section{Considering the capacitances in impedance-based fault location methods}

As commented before, in impedance-based fault locations methods impedance is calculated from voltages and currents registered at substation during the fault. In order to considered capacitances in the model, for singleline-to-ground faults the measured current should be corrected before applying the algorithm.

a) Capacitance due to cables.

The capacitance corresponding to the non-faulted lines that are connected to the same busbar as the faulted one can be modelled by, Fig.2:

$C_{n f}=\sum_{k=2}^{n} C_{k}$

The value for the cable capacitance, which corresponds to the typical sections used in the systems that are being analysed, is around $0,250 \mu \mathrm{F} / \mathrm{km}$ [4]. Consequently, the effect of such capacitance can sensibly modify the matching between the estimated impedance and that one obtained form the line model.

The correction of the measured current would be: 


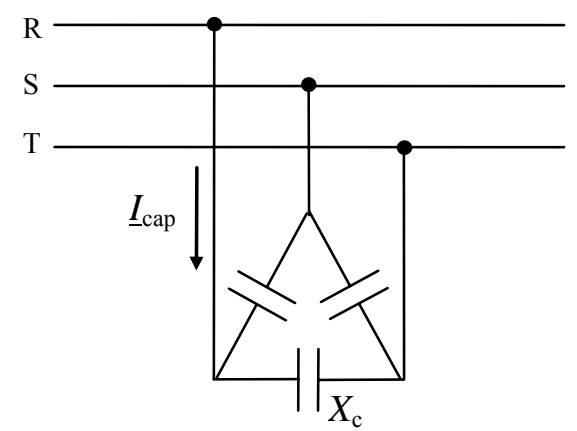

Fig. 3. Compensation capacitor bank.

$$
\underline{I}_{\text {measured }}^{\text {corr }}=\underline{I}_{\text {measured }}-\underline{U}_{\text {fault }} \cdot\left(-j \cdot X_{\text {Cnf }}\right)
$$

where $\underline{U}_{\text {fault }}$ is the voltage measured at the faulted phase.

b) Compensation capacitor bank.

In order to consider a compensation capacitor bank, the current in the faulted phase should be calculated starting from its reactance and the measured voltages. If the capacitor bank is delta connected, as it is shown in Figure 3 , and assuming that the fault occurs in phase $\mathrm{R}$, the current consumed in this phase can be calculated as follows:

$\underline{I}_{c a p}=\frac{\underline{U}_{\mathrm{RS}}+\underline{U}_{\mathrm{RT}}}{-j \cdot X_{C}}$

Then, the correction of the measured current would be:

$\underline{I}_{\text {measured }}^{\text {corr }}=\underline{I}_{\text {measured }}-\underline{I}_{\text {cap }}$

\section{Experimental results}

In order to check the proposed corrections in previous section, an analysis of two cases has been performed by following the next assumptions:

- Single-line-to-ground fault assuming an impedance fault, $Z_{\text {fault }}$, equal to 0 .

- Length of cable in non-faulted feeders equal to 30 $\mathrm{km}$.

- Capacitance of cables equal to $0.250 \mu \mathrm{F} / \mathrm{km}$.

- A 6 MVAr compensation capacitor bank is installed at the beginning of the faulted line.

The recorded voltages and currents are shown in Figures 4 and 5. These registers correspond to real data recorded during two single-line-to-ground faults in the same distribution line.

a) Fault 1.

From Figure 4, the fundamental frequency values during the fault for the faulted phase are:

$\underline{U}=3307.9 \angle-147^{\circ} \mathrm{V}$

$\underline{I}=508.9 \angle-161.9^{\circ} \mathrm{A}$

and the voltages in the non faulted phases are:
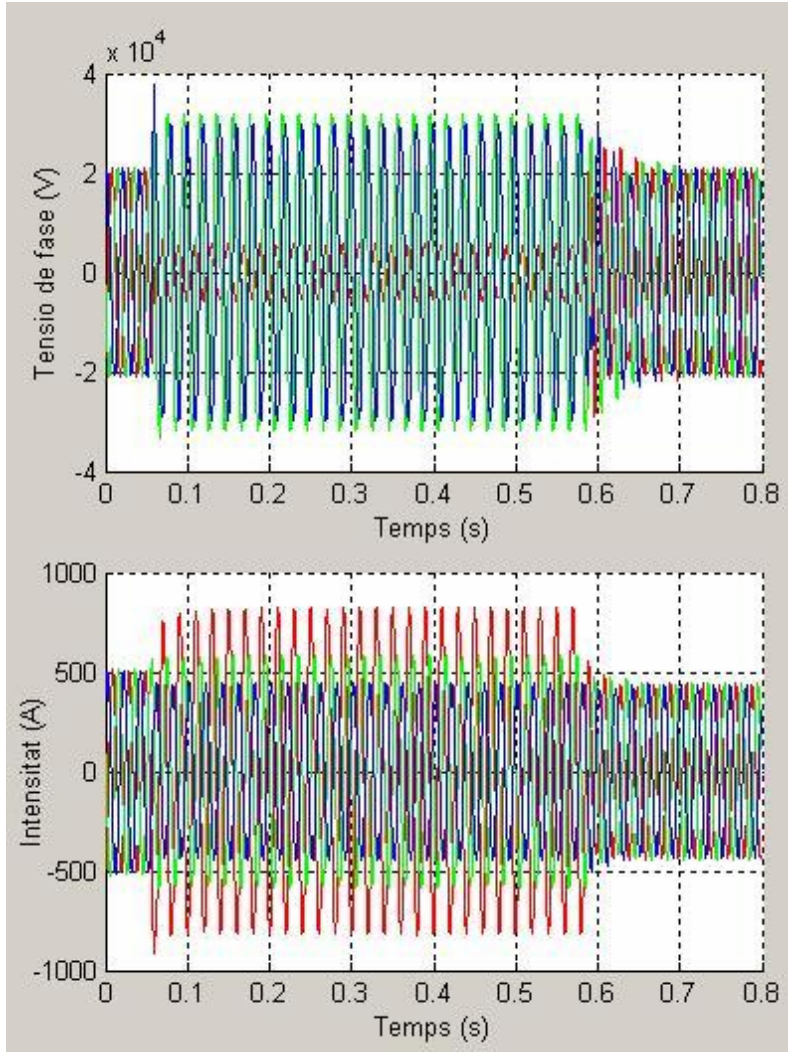

Fig. 4. Data recorded during fault \#1.Up: Phase-to-ground voltage (V); down: line current (A).
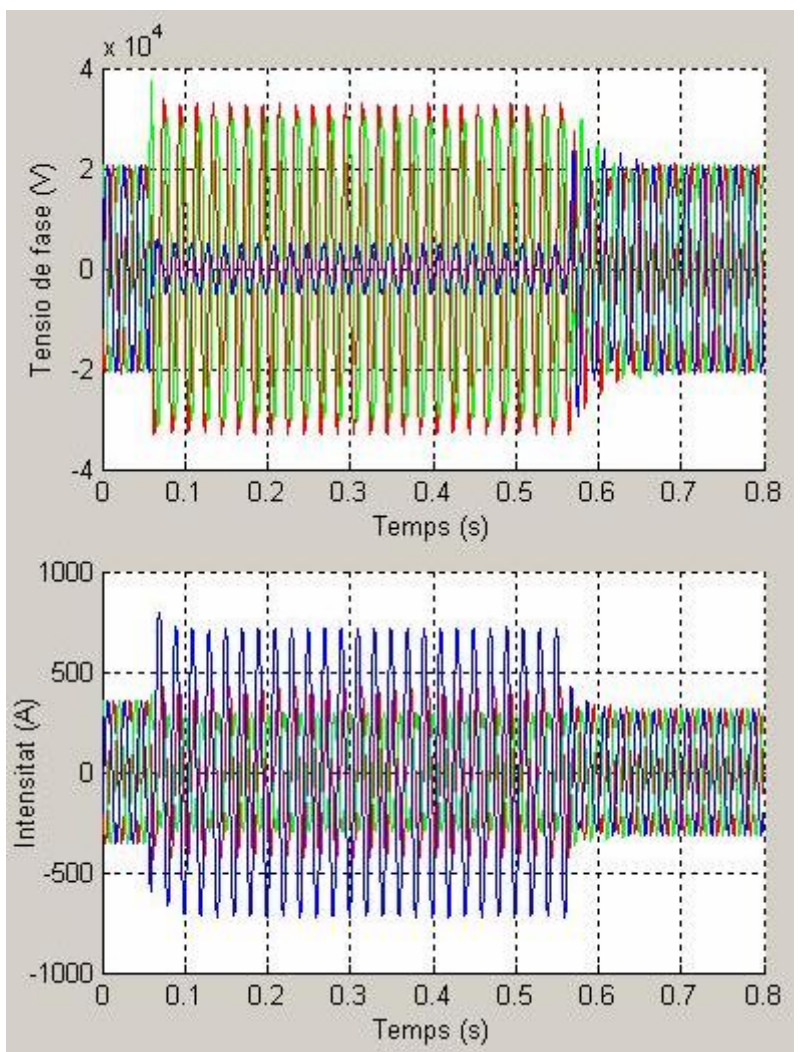

Fig. 5. Data recorded during fault \#2. Up: phase-to-ground voltage (V); down: line current (A).

$\underline{U}_{\mathrm{NF} 1}=23079.1 \angle 103.5^{\circ} \mathrm{V}$

$\underline{U}_{\mathrm{NF} 2}=21332.8 \angle 34.42^{\circ} \mathrm{V}$ 
From the voltage and current in the faulted phase, reactance seen from the monitoring location is calculated, $\mathrm{X}=1.67 \Omega$, and can be used in fault location algorithm.

If the capacitor bank is considered, assuming the assumptions commented previously, we obtain for the faulted phase $\underline{I}_{\text {cap }}=134.5 \angle-25^{\circ} \mathrm{A}$, which means that the modified current would be $\underline{I}^{\text {corr }}=614.1 \angle-170.5^{\circ}$ A. Now, with this corrected value, reactance would be $2.15 \Omega$ and the result of fault location algorithm would be closer to reality.

If the cables of non faulted lines are also considered, assuming the assumptions commented previously, the current due to their capacitances is $7.8 \angle-57^{\circ} \mathrm{A}$, which means that the modified current would be $\underline{I}^{\text {corr }}=617.2$ $\angle-171.2^{\circ}$ A. Now, with this corrected value, reactance would be $2.19 \Omega$. As it can be seen, considering cables of non faulted lines slightly modifies the reactance value and, in consequence, the fault location algorithm would give almost the same result considering or not considering the non faulted lines.

b) Fault 2 .

From Figure 5, the fundamental frequency values during the fault for the faulted phase are:

$\underline{U}=3754.5 \angle-165.6^{\circ} \mathrm{V}$

$\underline{I}=581.4 \angle 173.3^{\circ} \mathrm{A}$

and the voltages in the non faulted phases are:

$\underline{U}_{\mathrm{NF} 1}=22610.4 \angle 74.8^{\circ} \mathrm{V}$

$\underline{U}_{\mathrm{NF} 2}=20971.5 \angle 3.5^{\circ} \mathrm{V}$

From the voltage and current in the faulted phase, reactance seen from the monitoring location is calculated, $\mathrm{X}=2.33 \Omega$, and can be used in fault location algorithm.

If the capacitor bank is considered, assuming the assumptions commented previously, we obtain for the faulted phase $\underline{I}_{\text {cap }}=135.3 \angle-53.8^{\circ} \mathrm{A}$, which means that the modified current would be $\underline{I}^{\text {corr }}=680.8 \angle 165^{\circ} \mathrm{A}$. Now, with this corrected value, reactance would be 2.72 $\Omega$ and the result of fault location algorithm would be closer to reality.

If the cables of non faulted lines are also considered, assuming the assumptions commented previously, the current due to their capacitances is $8.85 \angle-75.6^{\circ} \mathrm{A}$, which means that the modified current would be $\underline{I}^{\text {corr }}=$ $685.15 \angle 164.3^{\circ}$ A. Now, with this corrected value, reactance would be $2.75 \Omega$. As it can be seen, considering cables of non faulted lines slightly modifies the reactance value and, in consequence, the fault location algorithm would give almost the same result considering or not considering the non faulted lines.

\section{Conclusions}

The paper presents how the presence of capacitances, due to lines or compensation banks, may influence in the location of single-phase-to-ground fault origin by using impedance-based fault location methods. Although the capacitance due to non faulted lines seems not affect significantly the result of the algorithm, the existence of compensation capacitor banks could be a factor that, if not considered, may affect the obtained result. Study is in a preliminary stage and should be completed with the analysis of real faults with known origin.

\section{Acknowledgement}

This research has been made possible by the interest and participation of ENDESA DISTRIBUCION and its Power Quality Department. It has also been supported by the Ministry of Education and Science under the research project DPI2006-09370.

\section{References}

[1] EN 50160: Voltage characteristics of electricity supplied by public distribution systems.

[2] M.H.J. Bollen, Understanding Power Quality Problems, Voltage Sags and Interruptions, John Wiley \& Sons, New York, USA, 2000.

[3] R. Das. "Determining the Locations of Faults in Distribution Systems", Ph.D. dissertation, University of Saskatchewan Saskatoon, Canada, Spring 1998.

[4] Cuaderno Técnico PT-004. Centros de transformación MT/BT. Schneider Electric. Noviembre 2000.

[5] Cuaderno Técnico $\mathrm{n}^{\mathrm{o}}$ 18. Análisis de las redes trifásicas en régimen perturbado con la ayuda de las componentes simétricas. Schneider Electric. Marzo 2000 . 